\title{
(2) OPEN ACCESS \\ Development and validation of a new clinical decision support tool to optimize screening for retinopathy of prematurity
}

\author{
Aldina Pivodic (D) , 'Helena Johansson, ${ }^{2,3}$ Lois E H Smith, ${ }^{4}$ Anna-Lena Hård, ${ }^{1}$ \\ Chatarina Löfqvist, ${ }^{1,5}$ Bradley A Yoder, ${ }^{6}$ M Elizabeth Hartnett, ${ }^{7}$ Carolyn Wu, ${ }^{4}$ \\ Marie-Christine Bründer, ${ }^{8}$ Wolf A Lagrèze, ${ }^{9}$ Andreas Stahl (i) , ${ }^{8}$ Abbas Al-Hawasi, ${ }^{10}$ \\ Eva Larsson (D) , ${ }^{11}$ Pia Lundgren (D) , ${ }^{1,12}$ Lotta Gränse, ${ }^{13}$ Birgitta Sunnqvist, ${ }^{14}$ \\ Kristina Tornqvist, ${ }^{13}$ Agneta Wallin, ${ }^{15}$ Gerd Holmström (D) , 11 \\ Kerstin Albertsson-Wikland, ${ }^{16}$ Staffan Nilsson, ${ }^{17,18}$ Ann Hellström (D) ${ }^{1}$
}

\begin{abstract}
- Additional supplemental material is published online only. To view, please visit the journal online (http://dx.doi. org/10.1136/bjophthalmol2020-318719).
\end{abstract}

For numbered affiliations see end of article.

\section{Correspondence to}

Aldina Pivodic, Department of Clinical Neuroscience, Institute of Neuroscience and Physiology, Sahlgrenska Academy, University of Gothenburg, Gothenburg, Sweden, Gothenburg S-416 85, Sweden; aldina.pivodic@gu.se

Received 22 December 2020 Revised 21 April 2021 Accepted 23 April 2021
Check for updates

(C) Author(s) (or their employer(s)) 2021. Re-use permitted under CC BY-NC. No commercial re-use. See rights and permissions. Published by BMJ.

\section{To cite: Pivodic A,}

Johansson H, Smith LEH,

et al. Br J Ophthalmol Epub

ahead of print: [please

include Day Month Year].

doi:10.1136/

bjophthalmol-2020-318719

\begin{abstract}
Background/Aims Prematurely born infants undergo costly, stressful eye examinations to uncover the small fraction with retinopathy of prematurity (ROP) that needs treatment to prevent blindness. The aim was to develop a prediction tool (DIGIROP-Screen) with 100\% sensitivity and high specificity to safely reduce screening of those infants not needing treatment. DIGIROP-Screen was compared with four other ROP models based on longitudinal weights. Methods Data, including infants born at 24-30 weeks of gestational age (GA), for DIGIROP-Screen development (DevGroup, $\mathrm{N}=6991$ ) originate from the Swedish National Registry for ROP. Three international cohorts comprised the external validation groups (ValGroups, $\mathrm{N}=1241$ ). Multivariable logistic regressions, over postnatal ages (PNAs) 6-14 weeks, were validated. Predictors were birth characteristics, status and age at first diagnosed ROP and essential interactions.
\end{abstract}

Results ROP treatment was required in 287 (4.1\%)/6991 infants in DevGroup and 49 (3.9\%)/1241 in ValGroups. To allow 100\% sensitivity in DevGroup, specificity at birth was $53.1 \%$ and cumulatively $60.5 \%$ at PNA 8 weeks. Applying the same cut-offs in ValGroups, specificities were similar (46.3\% and 53.5\%). One infant with severe malformations in ValGroups was incorrectly classified as not needing screening. For all other infants, at PNA 6-14 weeks, sensitivity was $100 \%$. In other published models, sensitivity ranged from $88.5 \%$ to $100 \%$ and specificity ranged from $9.6 \%$ to $45.2 \%$

Conclusions DIGIROP-Screen, a clinical decision support tool using readily available birth and ROP screening data for infants born GA 24-30 weeks, in the European and North American populations tested can safely identify infants not needing ROP screening. DIGIROP-Screen had equal or higher sensitivity and specificity compared with other models. DIGIROP-Screen should be tested in any new cohort for validation and if not validated it can be modified using the same statistical approaches applied to a specific clinical setting.

\section{INTRODUCTION}

Retinopathy of prematurity (ROP) is a sightthreatening disease occurring mainly in extremely preterm infants. ${ }^{1}$ Screening for severe ROP, for which treatment can prevent blindness, comprises repeated eye examinations following national screening guidelines, mostly using birth parameters, gestational age (GA) and birth weight. ${ }^{2}$ These examinations are stressful, costly and very inefficient. ${ }^{3-6}$ In Sweden and in the USA, only $\sim 6 \%$ of screened infants need treatment for $\mathrm{ROP}^{78}$ The number of ROP examinations and need for treatment are increasing over time with improved neonatal healthcare that increases the number of infants surviving extreme prematurity. ${ }^{9} 10$ A prediction model including known risk factors at birth and postnatal parameters using statistical approaches enabling risks to vary over time could identify the time to safely end ROP screening as well as identify low-risk infants requiring fewer or no ROP examinations. Such a clinical decision support tool would be valuable both for infants, and health economics. Reducing the number of examinations would not only reduce the stress and pain, but also for example, avoid the transport of infants to the screening unit, change of daily routines and potential exposure to infections during transport and at the hospital. Even if stress is minimised during ROP screening, the examinations may still affect the infants systemically with such as increased tachycardia and apnoeic episodes. From a health economics perspective, such models would help optimise the use of healthcare personnel to focus on the babies who need careful monitoring.

Many models predicting ROP requiring treatment have been published during the past two decades, such as weight, insulin-like growth factor 1, neonatal, ROP (WINROP), Colorado-ROP (COROP), Children's Hospital of Philadelphia-ROP (CHOP-ROP), postnatal growth and retinopathy of prematurity (G-ROP) and Omaha-ROP (OMAROP). ${ }^{11-20}$ A systematic review of 23 studies, performed by the American Academy of Ophthalmology (AAO) in 2016, developing or validating prediction models for different ROP outcomes found no model development study, and only one model validation study judged as good quality. ${ }^{21} 22$ The AAO concluded that prediction model development at the time was still in its early phase and 
needed rigorous implementation of guidelines for generating prognoses, including larger sample sizes and assessment of generalisability.

Our research group has previously published the prediction model (WINROP) which was based on birth parameters with the addition of first longitudinal serum insulin-like growth factor 1 (IGF-1) levels (that were difficult to obtain), then based on postnatal growth reflecting postnatal IGF-1. ${ }^{11} 122223$ This model, used to identify low-risk and high-risk infants, did not always achieve $100 \%$ sensitivity and had variable specificity. Recently, we published a prediction model for ROP requiring treatment, DIGIROP-Birth, for infants born at GA 24-30 weeks, estimating individual risks at an early stage based on birth characteristics alone (GA, birth weight and sex), as weight measurements at specific postnatal periods are not always available to the screening ophthalmologist and/or neonatologist. We applied statistical methods enabling description of the actual development of risk for severe ROP postnatally for each individual infant. $^{24}$

In the current study, we extended DIGIROP-Birth into DIGIROP-Screen to also include ROP progression data. Based on the estimated predictions we created a clinical decision support tool to reduce the burden of ROP screening sessions. As well as identifying infants who do not develop severe ROP in our cohort, we also sought to identify the time point when the longitudinal screening process could safely end in infants who had some risk of developing severe ROP during their postnatal course. To our knowledge this has not been studied previously. Internal and external validations, and comparisons (with respect to sensitivity and specificity of predicting severe ROP) to four other published models (WINROP, CO-ROP, CHOP-ROP, OMA-ROP), were performed. ${ }^{12}{ }^{16-18}$ The aim was to develop and validate models with $100 \%$ sensitivity to capture all infants requiring treatment and the highest specificity to reduce examinations in infants not developing severe ROP in our cohort and the validation cohorts using parameters that were easily available to ophthalmologists. The algorithm must be validated in any new cohort before being adopted to show that the same $100 \%$ sensitivity and high specificity apply. If $100 \%$ sensitivity and high specificity are not validated, using the same statistical approaches used in DIGIROP-Screen development the prediction model can be modified for any new clinical setting.

\section{MATERIALS AND METHODS}

This study has followed the guidelines for Transparent Reporting of a multivariable prediction model for Individual Prognosis or Diagnosis. $^{25}$

\section{Study population}

The data, including infants' birth characteristics and the timing of progression of ROP through stages and treatment, originate from the Swedish National Registry for ROP (SWEDROP) that is part of the Swedish Neonatal Register, and was initiated in $2007 .^{726}$ The registry has high coverage, $\sim 97 \%$, and collects data about the number of eye exams, dates for first and last eye exam, presence of ROP at the first eye screening, ROP stage, zone, plus disease, treatment, type of ROP, maximum stage and most central zone for ROP left and right eye and the date for first observation of respective ROP stage. The incomplete and missing data were validated against medical records. A study flowchart describing model development group and validation groups is presented in figure 1.

\section{Model development group (DevGroup)}

Of 7031 infants born at GA 24-30 weeks, between 1 January 2007 and 24 October 2017, 6991 (99.4\%) were eligible for inclusion in the model development group. Twenty-four $(0.3 \%)$ infants were excluded due to missing birth characteristics data and $13(0.2 \%)$ due to missing or inconsistent follow-up data. Additionally, three infants were identified as outliers during model development. They were treated despite not fulfilling treatment criteria for type 1 ROP (ROP stage 3 zone III, at the most one clock hour).

\section{Validation groups (ValGroups)}

Infants born at GA 24-30 weeks between 1 November 2017 and 7 August $2018(\mathrm{n}=318)$ and registered in SWEDROP were considered for inclusion in the Swedish temporal validation

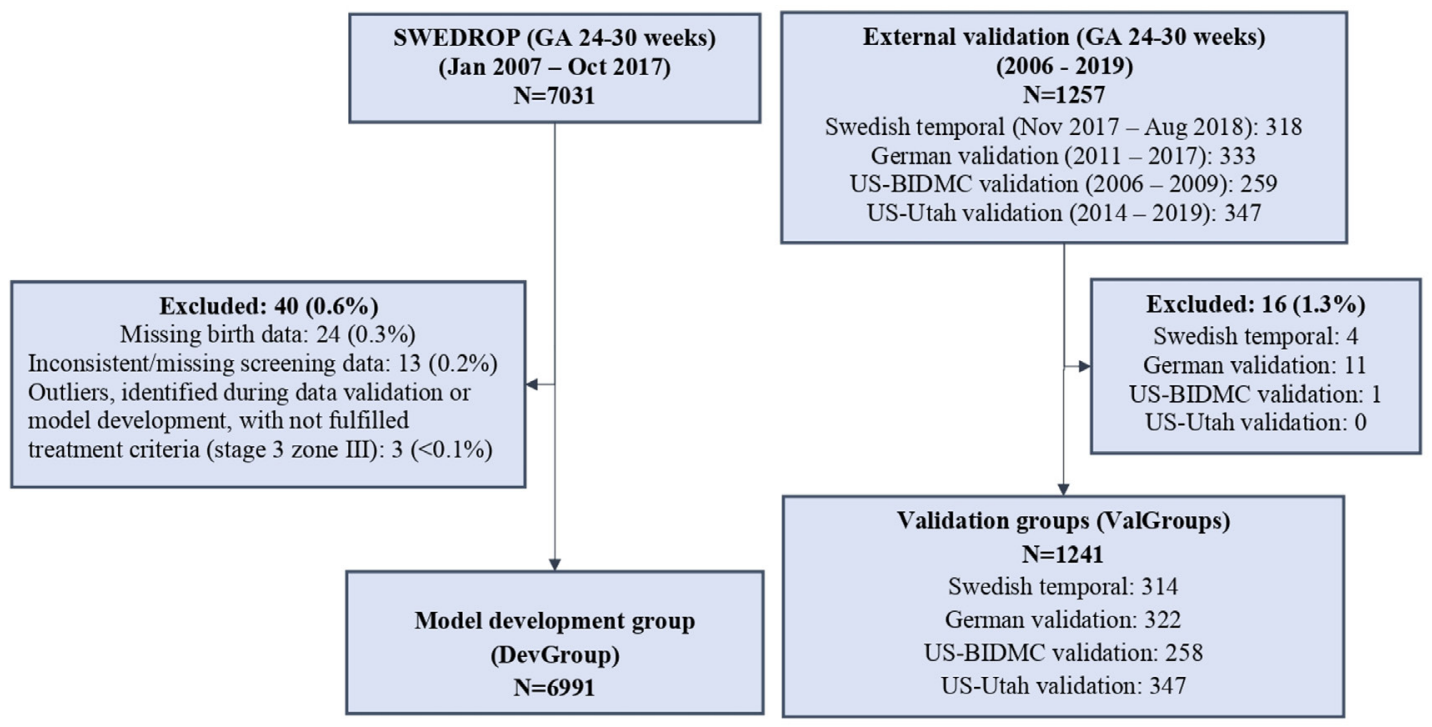

Figure 1 Study flowchart. BIDMC, Beth Israel Deaconess Medical Center; GA, gestational age; ROP, retinopathy of prematurity; SWEDROP, Swedish national Registry for ROP. 
group. Four (1.3\%) infants were excluded for missing data, leaving 314 (98.7\%) eligible infants for validation.

Retrospectively collected data from 2011 to 2017 from a German site in Freiburg included 322 (96.7\%) out of 333 infants born at GA $24-30$ weeks and served as the German validation group. ${ }^{27}$ Eleven (3.3\%) infants were excluded due to either missing birth weight or GA $(n=4)$, or unavailable ROP progression data $(\mathrm{n}=7)$.

The US-BIDMC validation group included 258 (99.6\%) out of 259 infants born at GA 24-30 weeks between 2006 and 2009 from the US site Beth Israel Deaconess Medical Center (BIDMC), Boston, Massachusetts. ${ }^{22}$ One infant was excluded due to unavailable ROP progression data. For this cohort, information about race and ethnicity was available in 240 (93.0\%)/258 and used to test the model's predictive ability for a white $(n=177)$ and a non-white $(n=63)$ population.

The US-Utah validation group included 347 (100\%)/347 infants born at GA 24-30 weeks between 2014 and 2019 from the US site John A. Moran Eye Center, Salt Lake City, Utah.

The two US cohort files contained infants' weekly weights and were used to compare four other ROP models (WINROP, CO-ROP, CHOP-ROP, OMA-ROP) using postnatal weight gain as input. ${ }^{12} 16-18$

In total, 1241 infants were included in the validation groups (ValGroups).

\section{Study procedures}

Fetal ultrasound was used to estimate GA in all cohorts. The postnatal age (PNA), postmenstrual age and GA are defined according to the American Academy of Pediatrics policy. ${ }^{28}$ Birth weight standard deviation scores (BWSDS) were calculated based on birth weight, GA and sex using a Swedish reference for 800000 healthy singletons (of $\sim 1$ million born) born at GA $\geq 24$ weeks during 1990-1999..$^{29}$

\section{Study outcome and predictors}

The study outcome is ROP treated following early treatment for ROP criteria or if judged required by the examining/treating ophthalmologist. ${ }^{30}$ ROP stages were defined by the International Classification of ROP. ${ }^{31}$ The infant's status (yes/no), age at the first sign of ROP and weeks since the first sign of ROP were potential predictors tested for inclusion in the DIGIROP-Screen model, besides the log-odds for the DIGIROP-Birth probabilities $(\log ($ probability/(1-probability $)))$, GA, sex, BWSDS and important interactions. The final models included log-odds for the DIGIROP-Birth probabilities, infant's status and age at the first sign of ROP and interaction between them. Data were analysed on patient-level, including first occurrence of any ROP as predictor and first ROP treatment as outcome.

\section{Statistical analysis}

Continuous variables were presented by mean, SD, median and range and categorical variables by number and percentage. The difference between DevGroup and ValGroups was tested using Fisher's exact test for dichotomous variables, MantelHaenszel $\chi^{2}$ trend test for ordered categorical variables and Mann-Whitney U test for continuous variables. The estimated risk predictions from DIGIROP-Birth were applied at birth. Multivariable logistic regression was used for PNAs 6-14 weeks. PNA week 6 is the earliest week when infants are starting their screening per guidelines. By PNA week 14 it was expected that majority of ROP treatments have occurred. GA-specific cutoffs based on estimated probabilities for $100 \%$ sensitivity were retrieved from the models performed on DevGroup and used for implementation of the clinical decision support tool. Specificities and cumulative specificities that is a fraction of infants below the cut-off at the current time or earlier among the non-treated infants were obtained with 95\% CI. Internal validation, examining the model's reproducibility in its cohort, was performed by 10 -fold cross-validation. The Hosmer-Lemeshow test examined goodness-of-fit and calibration of observed versus the estimated number of events. External validation, analysing the model's generalisability/transportability in the cohorts from other healthcare settings, populations and periods were assessed on ValGroups by describing sensitivity, specificity and cumulative specificity with 95\% CI based on cut-offs for 100\% sensitivity obtained from DevGroup. In order to achieve the recommended lower 95\% limit for 100\% sensitivity of 99\%, 300 events (ROP treatment) were needed, that was fulfilled by the DevGroup sample. Sensitivity and cumulative specificity/specificity with 95\% CI were presented for DIGIROP-Screen and the four ROP comparison models based on the two US external validation cohorts combined. Detailed descriptions of the statistical methods are available in online supplemental eappendix 1 . Graphical workflow of DIGIROP-Screen and four comparison models are presented in online supplemental efigure 1 .

All tests were two-tailed and $\mathrm{p}<0.05$ was considered significant. Analyses were performed using SAS software V.9.4 (SAS Institute Inc, Cary, North Carolina, USA).

\section{RESULTS}

\section{Study population}

Birth characteristics and ROP progression for the DevGroup $(\mathrm{N}=6991)$ and the four cohorts included in the ValGroups $(\mathrm{N}=1241)$ are presented in table 1 . In the DevGroup, 3158 (45.2\%) were girls. Mean GA was 28.3 (SD 1.9) weeks, mean birth weight 1146 (SD 339, range 307-3245) grams and mean BWSDS - 1.03 (SD 1.37). In DevGroup and ValGroups, respectively, $2026(29.0 \%)$ and $502(40.5 \%)$ were diagnosed with any ROP, and 287 (4.1\%) and 49 (3.9\%) were treated for ROP.

ValGroups included more girls, had lower average birth weight, differed with respect to the birth year and more infants experienced any ROP compared with DevGroup. Online supplemental etable 1 describes infant characteristics for the validation cohorts and online supplemental etable 2 for treated and not treated infants.

\section{DIGIROP-Screen in model development group (DevGroup)}

The multivariable logistic models for DIGIROP-Screen at birth and over PNAs 6-14 weeks are presented in online supplemental etable 3 and cut-offs based on estimated probabilities in online supplemental etable 4. Estimated probabilities for ROP treatment stratified by GA at birth (24-30 weeks) for different PNA are presented in online supplemental efigure 2 A-J. The area under the receiver operating characteristic curve (AUC) ranged between 0.91 and 0.93 (online supplemental etable 5, efigure 3). For selected cut-offs for 100\% (95\% CI: $98.7 \%$ to $100 \%)$ sensitivity in DevGroup, specificity at birth was $53.1 \%$ (95\% CI: $51.9 \%$ to $54.3 \%$ ), cumulatively at 8 weeks $60.5 \%$ (95\% CI: $59.3 \%$ to $61.7 \%$ ) and cumulatively at 12 weeks PNA $75.5 \%$ (95\% CI: $74.5 \%$ to $76.5 \%$ ) (table 2 , online supplemental etable 6 , efigure 4 ). The prediction models' contribution at 6,7 and 14 weeks PNA to the increase of cumulative specificity was negligible. Among infants flagged as not needing ROP screening already at birth 3179 (89.2\%) were diagnosed with no ROP, 202 $(5.7 \%)$ with ROP stage 1,137 (3.8\%) with untreated stage 2 and 


\begin{tabular}{|c|c|c|c|}
\hline & $\begin{array}{l}\text { Model development } \\
\text { group } \\
(\mathrm{N}=6991)\end{array}$ & $\begin{array}{l}\text { Validation groups } \\
(\mathrm{N}=1241)\end{array}$ & $P$ value ${ }^{*}$ \\
\hline Girls & 3158 (45.2\%) & 607 (48.9\%) & 0.016 \\
\hline GA at birth (weeks) & $\begin{array}{l}28.3(1.9) \\
28.6(24.0 ; 30.9)\end{array}$ & $\begin{array}{l}28.0(1.9) \\
28.3(24.0 ; 30.9)\end{array}$ & $<0.0001$ \\
\hline GA (full weeks) & & & 0.0007 \\
\hline 24 & $427(6.1 \%)$ & $94(7.6 \%)$ & \\
\hline 25 & $597(8.5 \%)$ & $114(9.2 \%)$ & \\
\hline 26 & $781(11.2 \%)$ & $129(10.4 \%)$ & \\
\hline 27 & $914(13.1 \%)$ & $187(15.1 \%)$ & \\
\hline 28 & $1141(16.3 \%)$ & $239(19.3 \%)$ & \\
\hline 29 & $1419(20.3 \%)$ & $236(19.0 \%)$ & \\
\hline 30 & $1712(24.5 \%)$ & $242(19.5 \%)$ & \\
\hline Birth weight (grams) & $\begin{array}{l}1146(339) \\
1135(307 ; 3245)\end{array}$ & $\begin{array}{l}1068(319) \\
1065(335 ; 2450)\end{array}$ & $<0.0001$ \\
\hline $\begin{array}{l}\text { Birth weight SDS (Niklasson and } \\
\text { Albertsson-Wikland 2008) }\end{array}$ & $\begin{array}{l}-1.03(1.37) \\
-0.77(-8.56 ; 4.93)\end{array}$ & $\begin{array}{l}-1.31(1.57) \\
-0.99(-9.92 ; 2.75)\end{array}$ & $<0.0001$ \\
\hline Birth year & & & $<0.0001$ \\
\hline 2006-2007 & $543(7.8 \%)$ & $139(11.2 \%)$ & \\
\hline $2008-2009$ & $1331(19.0 \%)$ & $119(9.6 \%)$ & \\
\hline 2010-2011 & $1303(18.6 \%)$ & $9(0.7 \%)$ & \\
\hline $2012-2013$ & $1369(19.6 \%)$ & $103(8.3 \%)$ & \\
\hline 2014-2015 & $1445(20.7 \%)$ & $249(20.1 \%)$ & \\
\hline 2016-2017 & $1000(14.3 \%)$ & $331(26.7 \%)$ & \\
\hline 2018-2019 & $0(0.0 \%)$ & $291(23.4 \%)$ & \\
\hline Any ROP & $2026(29.0 \%)$ & $502(40.5 \%)$ & $<0.0001$ \\
\hline $\begin{array}{l}\text { PNA at first diagnosed ROP } \\
\text { (weeks) }\end{array}$ & $\begin{array}{l}8.35(2.22) \\
8.14(3.43 ; 18.71)\end{array}$ & $\begin{array}{l}8.07(2.56) \\
7.71(3.14 ; 19.00)\end{array}$ & \\
\hline ROP treatment & $287(4.1 \%)$ & $49(3.9 \%)$ & 0.87 \\
\hline PNA at ROP treatment (weeks) & $\begin{array}{l}12.8(2.8) \\
12.4(7.0 ; 21.9)\end{array}$ & $\begin{array}{l}12.3(2.4) \\
11.9(7.1 ; 19.6)\end{array}$ & \\
\hline
\end{tabular}

Model development group includes data from Swedish National Registry for ROP, born at GA 24-30 weeks (2007-2017).

Validation groups consist of four external validation cohorts, one from Sweden (later time period than in the model development group), one from Germany and two from USA. For categorical variables, $\mathrm{n}(\%)$ is presented. For continuous variables, mean (SD)/median $(\min ; \max )$ is given.

${ }^{*}$ P values should be interpreted with caution due to the large cohorts. Conclusions should be made based on the clinically relevant differences.

GA, gestational age; PNA, postnatal age; ROP, retinopathy of prematurity; ROP, retinopathy of prematurity; SDS, standard deviation score.

44 (1.2\%) with untreated stage 3 (online supplemental etable 7). No infants born at GA 24 and 25 weeks could be released from ROP screenings at birth (figure 2A). Percentages of infants identified as possible to be released from ROP screenings over PNA stratified by GA at birth are presented in figure $2 \mathrm{~B}$.

Stratified by GA $<28$ and $\geq 28$ weeks, specificity at birth was $11.9 \%$ and $76.8 \%$, and cumulatively up to 12 weeks $40.6 \%$ and $95.5 \%$, respectively (online supplemental etable 6 ). The corresponding specificities for GA $<30$ weeks were $37.4 \%$ at birth and $67.1 \%$ cumulatively up to 12 weeks PNA.

\section{Internal validation of DIGIROP-Screen in model development group (DevGroup)}

Specificity, cumulative specificity and AUC with 95\% CI obtained from the 10-fold cross-validation were obtained from logistic regression models developed on DevGroup (online supplemental etable 5 and 6). The AUC ranged between 0.90 and 0.94 (online supplemental etable 5). The specificity at birth was $48.0 \%$ (95\% CI: $46.8 \%$ to $49.2 \%$ ),
Table 2 Specificity with $95 \% \mathrm{Cl}$ for $100 \%$ sensitivity at birth and over postnatal weeks for model development group $(\mathrm{N}=6991)$, and external validation groups $(\mathrm{N}=1241)$

\begin{tabular}{|c|c|c|}
\hline & $\begin{array}{l}\text { Model development group } \\
\text { (DevGroup)* }^{*}\end{array}$ & $\begin{array}{l}\text { External validation } \\
\text { (ValGroups) } \dagger\end{array}$ \\
\hline & $\begin{array}{l}\text { Specificity }(95 \% \mathrm{Cl}) \\
\mathrm{N}=6991\end{array}$ & $\begin{array}{l}\text { Specificity }(95 \% \mathrm{Cl}) \\
\mathrm{N}=1241\end{array}$ \\
\hline At birth & 53.1 (51.9 to 54.3$)$ & 46.3 (43.4 to 49.2$)$ \\
\hline Cumulatively at PNA 6 weeks & 53.3 (52.0 to 54.5$)$ & 46.4 (43.5 to 49.3$)$ \\
\hline Cumulatively at PNA 7 weeks & $54.2(53.0$ to 55.4$)$ & 47.2 (44.4 to 50.1$)$ \\
\hline Cumulatively at PNA 8 weeks & 60.5 (59.3 to 61.7$)$ & 53.5 (50.6 to 56.4 ) \\
\hline Cumulatively at PNA 9 weeks & $67.6(66.5$ to 68.7$)$ & 61.2 (58.3 to 63.9$)$ \\
\hline Cumulatively at PNA 10 weeks & 72.1 (71.0 to 73.2$)$ & 65.9 (63.1 to 68.5$)$ \\
\hline Cumulatively at PNA 11 weeks & 75.3 (74.3 to 76.4$)$ & 69.3 (66.6 to 71.9$)$ \\
\hline Cumulatively at PNA 12 weeks & 75.5 (74.5 to 76.5$)$ & 69.6 (66.9 to 72.2$)$ \\
\hline Cumulatively at PNA 13 weeks & 80.6 (79.6 to 81.5$)$ & 75.2 (72.6 to 77.6$)$ \\
\hline Cumulatively at PNA 14 weeks & 80.6 (79.7 to 81.6$)$ & 75.2 (72.6 to 77.6$)$ \\
\hline
\end{tabular}

Model development group includes data from SWEDROP, born at GA of 24-30 weeks (2007-2017).

Validation groups consist of four external validation cohorts, one from Sweden (later time period than in model development group), one from Germany and two from USA.

Cumulative specificity at a certain PNA is calculated as a union of specificities up to and including that certain PNA.

${ }^{*}$ Cut-offs selected in model development group for sensitivity $100 \%$.

tFor validation groups, cut-offs obtained from model development group are applied. Sensitivity 100\% for all postnatal weeks except for one infant at birth, and PNA 6 and 7 weeks (sensitivity $48 / 49$ at those time points), with severe comorbidity profile.

GA, gestational age; PNA, postnatal age; ROP, retinopathy of prematurity; SWEDROP, Swedish National Registry for ROP.

and cumulatively up to PNA 8 weeks was $60.0 \%$ (95\% CI: $58.8 \%$ to $61.1 \%$ ) for internal validation.

Hosmer-Lemeshow test was non-significant at all PNAs (online supplemental etable 3), indicating goodness-of-fit accepted as satisfactory, and showed a well-calibrated estimated versus the observed number of events.

\section{External validation of DIGIROP-Screen in validation groups (ValGroups)}

Individual risk predictions stratified by GA at birth (24-30 weeks) over PNA are presented in online supplemental efigure 5.

Applying the same cut-offs on ValGroups, as those obtained for DevGroup (for 100\% sensitivity), the specificities were $46.3 \%$ (95\% CI: $43.4 \%$ to $49.2 \%$ ) at birth, $53.5 \%$ (95\% CI: $50.6 \%$ to $56.4 \%$ ) cumulatively at 8 weeks and $69.6 \%(95 \%$ CI $66.9 \%$ to $72.2 \%)$ cumulatively at 12 weeks PNA (table 2, online supplemental etable 6, efigure 6). In ValGroups, sensitivity was 100\% (95\% CI: $92.7 \%$ to $100 \%$ ) for all models except for one infant at birth and PNAs 6 and 7 weeks. By inclusion criteria for current ROP screening, this infant should have been followed and screened because of the medical indication. At birth (GA 30 weeks) the infant had VACTERL association (vertebral defects, anal atresia, cardiac defects, tracheo-esophageal fistula, renal abnormalities, limb abnormalities) with severe intrauterine growth restriction.

Stratified by GA $<28$ and $\geq 28$ weeks, specificity at birth was $11.3 \%$ and $69.7 \%$, and cumulatively up to 12 weeks $35.4 \%$ and $92.6 \%$, respectively.

Figure 2C and online supplemental efigure 7 illustrate the number of infants who could potentially be released from ROP screening cumulatively over PNAs according to last examination reported in SWEDROP, according to DIGIROPScreen in DevGroup and ValGroups. 
A

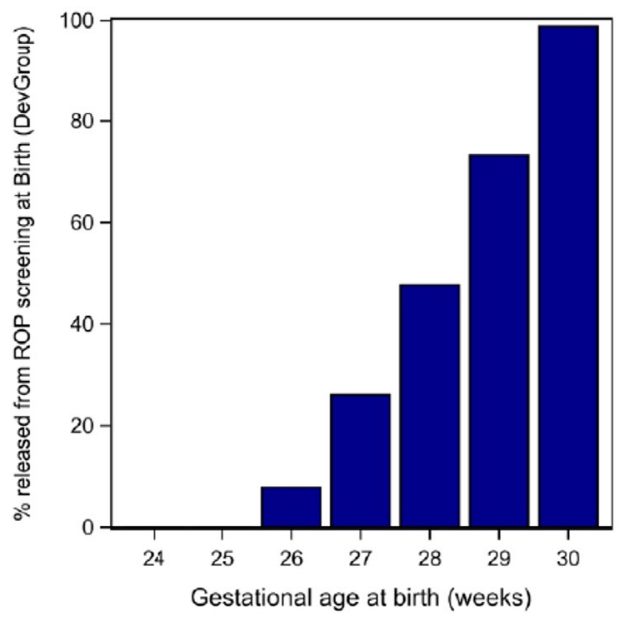

B

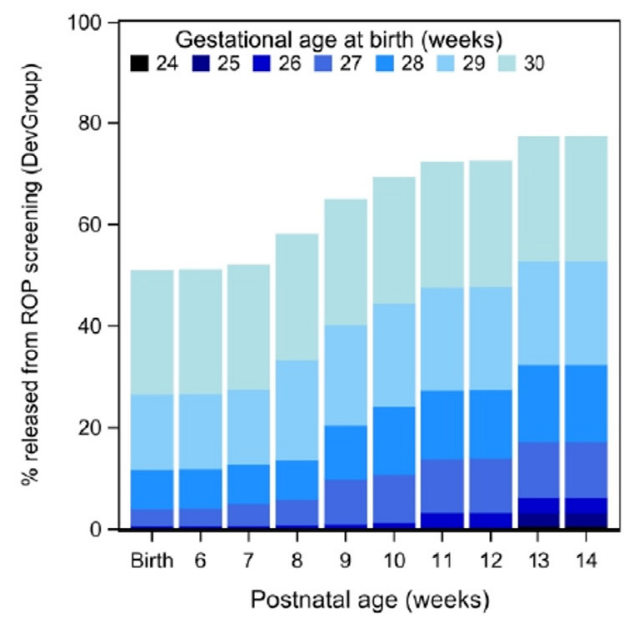

C

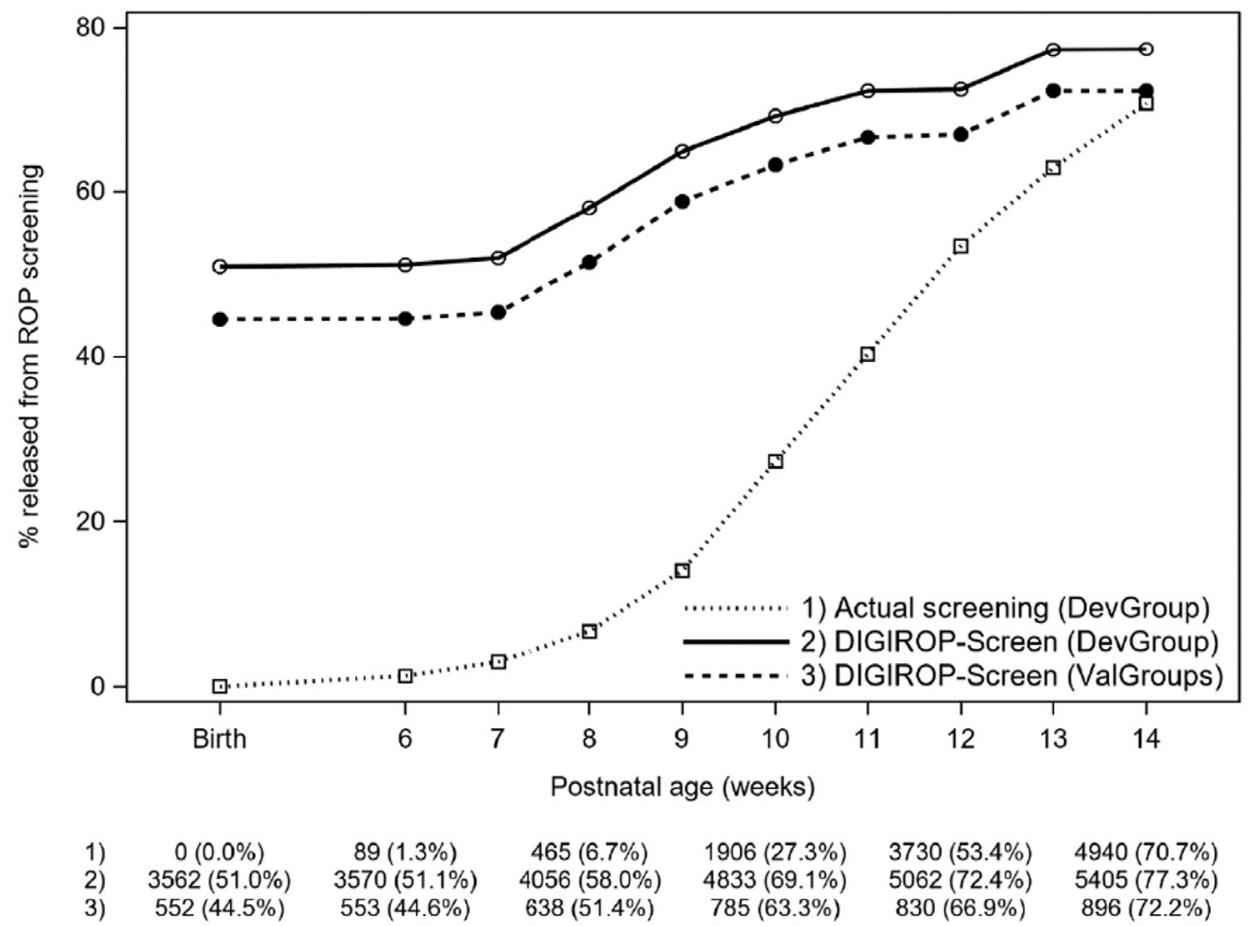

Figure 2 Illustration of infants born 24-30 weeks of gestational age released from screening for ROP according to: (A) risk predictions from DIGIROP-Screen at birth by gestational age in model development group (DevGroup), (B) risk predictions from DIGIROP-Screen over postnatal ages by gestational age in DevGroup, (C) last examination date reported in SWEDROP, and risk predictions from DIGIROP-Screen in DevGroup and validation groups (ValGroups). In (C), n and \% are presented for time points: birth, postnatal ages 6, 8, 10, 12 and 14 weeks. ROP, retinopathy of prematurity; SWEDROP, Swedish National Registry for ROP.

Information about race and ethnicity was available in the US-BIDMC validation group. Stratifying by infants reported as white ( $\mathrm{n}=177$, one required ROP treatment) and those reported as non-white $(n=63$, three required ROP treatment) infants, specificity at birth was $54.5 \%$ and $38.3 \%$, and cumulatively up to 12 weeks $65.9 \%$ and $56.7 \%$, respectively (online supplemental etable 6).

The AUC for the models at birth and over different PNAs ranged between 0.88 and 0.92 (online supplemental etable 5).

\section{Comparison of DIGIROP-Screen to other ROP prediction models}

DIGIROP-Screen was compared with four other published models using US validation groups, as comparison cohorts table 3 .

With $100 \%$ sensitivity cut-off, DIGIROP-Screen versus $\mathrm{CHOP}^{-\mathrm{ROP}^{17}}$ had better specificity $(48.7 \%$ vs $27.5 \%)$ at 8 weeks and better specificity at 12 weeks PNA (63.6\% vs $27.9 \%)$. DIGIROP-Screen versus OMA-ROP ${ }^{18}$ had the same sensitivity 
Table 3 Comparison of DIGIROP-Screen versus other existing ROP prediction models

\begin{tabular}{|c|c|c|c|c|}
\hline \multirow[b]{2}{*}{ Comparison model and time point } & \multicolumn{2}{|c|}{$\begin{array}{l}\text { N/N } \\
\text { Specificity }(95 \% \mathrm{Cl})(\%)\end{array}$} & \multicolumn{2}{|c|}{$\begin{array}{l}\mathrm{N} / \mathrm{N} \\
\text { Sensitivity }(95 \% \mathrm{Cl})(\%)\end{array}$} \\
\hline & DIGIROP-Screen & Comparison ROP model & DIGIROP-Screen & Comparison ROP model \\
\hline $\begin{array}{l}\text { DIGIROP-Screen (up to PNA } 8 \text { w) vs CHOP-ROP }{ }^{17} \text { (up to } \\
\text { PNA } 8 \text { w) }\end{array}$ & $\begin{array}{l}278 / 571 \\
48.7 \\
\text { (44.5 to } 52.9)\end{array}$ & $\begin{array}{l}157 / 571 \\
27.5 \\
\text { (23.9 to } 31.4)\end{array}$ & $\begin{array}{l}26 / 26 \\
100.0 \\
(86.8 \text { to } 100.0)\end{array}$ & $\begin{array}{l}26 / 26 \\
100.0 \\
(86.8 \text { to } 100.0)\end{array}$ \\
\hline $\begin{array}{l}\text { DIGIROP-Screen (up to PNA } 12 \text { w) vs CHOP-ROP' (up to } \\
\text { PNA } 12 \text { w) }\end{array}$ & $\begin{array}{l}362 / 569 \\
63.6 \\
\text { (59.5 to } 67.6)\end{array}$ & $\begin{array}{l}159 / 569 \\
27.9 \\
\text { (24.3 to } 31.8)\end{array}$ & $\begin{array}{l}26 / 26 \\
100.0 \\
(86.8 \text { to } 100.0)\end{array}$ & $\begin{array}{l}26 / 26 \\
100.0 \\
(86.8 \text { to } 100.0)\end{array}$ \\
\hline $\begin{array}{l}\text { DIGIROP-Screen (up to PMA } 36 \text { w) vs OMA-ROP }{ }^{18} \text { (up to } \\
\text { PMA } 36 \text { w) }\end{array}$ & $\begin{array}{l}250 / 541 \\
46.2 \\
\text { (41.9 to } 50.5)\end{array}$ & $\begin{array}{l}206 / 541 \\
38.1 \\
\text { (34.0 to } 42.3)\end{array}$ & $\begin{array}{l}24 / 25 \\
96.0 \\
(79.6 \text { to } 99.9)\end{array}$ & $\begin{array}{l}24 / 25 \\
96.0 \\
(79.6 \text { to } 99.9)\end{array}$ \\
\hline $\begin{array}{l}\text { DIGIROP-Screen (up to WINROP risk flag or last } \\
\text { measurement) vs } \\
\text { WINROP'12 }\end{array}$ & $\begin{array}{l}256 / 568 \\
45.1 \\
\text { (40.9 to } 49.3)\end{array}$ & $\begin{array}{l}257 / 568 \\
45.2 \\
\text { (41.1 to } 49.4)\end{array}$ & $\begin{array}{l}25 / 26 \\
96.2 \\
\text { (80.4 to } 99.9)\end{array}$ & $\begin{array}{l}23 / 26 \\
88.5 \\
\text { (69.8 to } 97.6)\end{array}$ \\
\hline 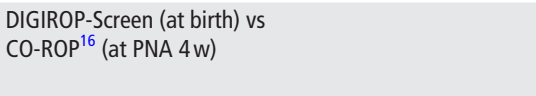 & $\begin{array}{l}231 / 564 \\
41.0 \\
(36.9 \text { to } 45.1)\end{array}$ & $\begin{array}{l}54 / 564 \\
9.6 \\
\text { (7.3 to } 12.3)\end{array}$ & $\begin{array}{l}25 / 26 \\
96.2 \\
(80.4 \text { to } 99.9)\end{array}$ & $\begin{array}{l}25 / 26 \\
96.2 \\
\text { (80.4 to } 99.9)\end{array}$ \\
\hline
\end{tabular}

CHOP-ROP, Children's Hospital of Philadelphia-ROP; CO-ROP, Colorado-ROP; OMA-ROP, Omaha ROP; PMA, postmenstrual age; PNA, postnatal age; ROP, retinopathy of prematurity; w, weeks; WINROP, weight, insulin-like growth factor 1 , neonatal, ROP.

(96.0\% vs $96.0 \%)$, but better specificity $(46.2 \%$ vs $38.1 \%)$. DIGIROP-Screen versus WINROP ${ }^{12}$ had better sensitivity (96.2\% vs $88.5 \%)$ and similar specificity $(45.1 \%$ vs $45.2 \%)$. DIGIROP-Screen applied at birth versus CO-ROP ${ }^{16}$ had similar sensitivity (96.2\% vs $96.2 \%)$ and better specificity $(41.0 \%$ vs 9.6\%).

\section{Clinical implications}

The DIGIROP-Screen prediction tool comprising automatically calculated individual risk predictions for infants born at GA 24-30 weeks is available at www.digirop.com. ${ }^{32}$ Additionally, evaluations of the risks based on defined cut-offs provide information whether any/further ROP examinations are required or not for $100 \%$ sensitivity (in these cohorts). Example illustrations following a specific infant over screening PNAs planned for availability in the application are presented in online supplemental efigure 8 .

\section{DISCUSSION}

In this study, we developed an ROP clinical decision support tool, DIGIROP-Screen, for infants born at GA 24-30 weeks, suitable for longitudinal use with ROP screening. The tool is developed to identify the time point for safe release of an infant from the ROP screening. DIGIROP-Screen is based on the infants' birth characteristics (GA, birth weight and sex) and ROP data that are easily obtained at almost all medical facilities while performing routine ROP screening. Other models use longitudinal weights at specific intervals which are less readily available to ophthalmologists and less retrievable on a national level for all screened infants. The prediction tool applied to several cohorts of infants screened for ROP by current criteria in advanced neonatal intensive care unit (NICU) settings, identified early $\sim 45 \%$ of infants as not needing any ROP screening using only neonatal characteristics and identified an additional 25\% for whom screening may be terminated earlier than with today's screening practice, thus potentially substantially and safely reducing the number of screening examinations. The prediction tool is made available as an online application, www.digirop.com, to clinicians worldwide. This tool must be validated and assessed in each specific clinical setting, before being implemented for routine use. Using the same statistical approaches used in DIGIROP-Screen development the prediction model can be modified for any new clinical setting.

Studying a low-incidence disease requiring 100\% sensitivity, that is, correctly identified all high-risk infants requiring ROP treatment, implies the need for access to very large datasets. The lower 95\% confidence limit for sensitivity would need to approach 99\%, as previously discussed. ${ }^{21} 33$ Our study, which included $\sim 7000$ infants and 287 endpoints (ie, ROP treatment), reaches this goal. Larger datasets imply larger individual variability and thus also increased risk for outlying data in the cohort. Having the diagnostic cut-offs in such large datasets based on the individually estimated risks (potentially including outliers) together with the requirement of $100 \%$ sensitivity, most often results in low specificity, that is, correctly identified all low-risk infants not needing treatment that might be released from the ROP screening. In the external validation, DIGIROPScreen demonstrated specificity of $46 \%$ at birth (11\% for GA $<28$ weeks, $70 \%$ for GA $\geq 28$ weeks), and $70 \%$ for data used up to postnatal week 12 (35\% for GA $<28$ weeks, 93\% for GA $\geq 28$ weeks), compared with $11 \%$ with the updated CHOP-ROP model using longitudinal weekly weights and 33\% for the G-ROP algorithm that screens all infants $<28$ weeks of GA at birth. ${ }^{17}$ Smaller datasets, on the other hand, including 191 to 560 infants in model development have resulted in higher specificities ranging from $62 \%$ to $85 \%$ for achieved $100 \%$ sensitivity. ${ }^{12} 18{ }^{20}$ Nonetheless, in our US validation cohorts of $\sim 600$ infants, DIGIROP-Screen appeared to be a more accurate prediction model than the four comparison models, for both sensitivity and specificity. Unfortunately, the weight measurements at 10, 19, 20, 29, 30 and 39 postnatal days were not available for DIGIROP-Screen precluding a full comparison to the G-ROP screening criteria. ${ }^{34}$

The high performance of DIGIROP-Screen even at birth, applying only DIGIROP-Birth risk estimations, is achieved due to the availability of a large model development dataset and the most prominent risk factors for ROP treatment, GA and birth weight. However, as well known, these are not the only important risk factors, which is why the obtained probabilities showed high variability between GA that resulted in the decision to apply GA-specific cut-offs as scores rather than probabilities in the prediction tool. 
The infant with congenital VACTERL association was incorrectly flagged as not needing ROP screening. In current clinical practice, any very preterm baby with severe congenital malformations would have had continuous clinical and medical surveillance for ROP. The medical evaluation is of paramount importance, no matter how high predictive ability is achieved of any model. Likewise, babies born before 24 weeks of GA are all at a very high risk for developing ROP (89\%) and all should be followed closely. ${ }^{24}$ Optimisation of screening through general prediction models for these babies is inapplicable and inappropriate.

Our study's strength is the large national cohort, the validation datasets originating from two continents and the selected statistical methods. Development, validation and evaluation of the prediction tool followed the prognostic research guidelines. ${ }^{25}$ Another strength is the wide availability of birth and ROP progression data and easy access to the model that might facilitate screening for ophthalmologists. Identification of infants as potentially requiring no further screening after a defined date may safely decrease the number of unnecessary examinations for low-risk infants after affirming that the model applies to the particular cohort under consideration.

Our study's limitation is its retrospective design and registry data, although intense efforts were made to validate incomplete data points. Ongoing research including photographic documentation and telemedicine will certainly decrease the variability in ROP diagnostics between ophthalmologists, and hence also improve sensitivity and specificity of prediction models. ${ }^{35}$ A second limitation is the small subgroup of non-white infants used for validation. In many countries, screening of infants born $<31$ weeks of GA is mandatory, although in Sweden the current guidelines from 2020 recommend screening for GA $<30$ weeks. ${ }^{736-38}$ Our tool was developed to study infants born at GA 24 weeks (+ 0 days) to 30 weeks (+6 days). However, infants born at 31 weeks of GA or later who require screening based on a medical indication should be monitored closely and carefully, as should infants born $<24$ weeks of GA, all of whom have a high risk for developing ROP needing treatment. This algorithm which is aimed at identifying the time point for ending ROP screening is thus of limited value to these babies as they need screening according to guidelines. Another limitation is that no validation has been performed on populations from low-income countries where more mature infants need treatment for ROP due to the risk associated with unmonitored oxygen exposure, but also from countries with high-level neonatal care but with limited facilities and personnel. Continued validation, performed on similar and different populations is needed. The model parameters or even the model selection, including other important variables, might need to be updated to match some specific healthcare settings. The future implementation of this tool at our or any other NICU should concomitantly initiate a clinical study monitoring its effectiveness (including stress reduction), impact on patient safety as well as on the clinical workload and health economics.

In conclusion, the DIGIROP-Screen, an internally and externally validated ROP prediction tool, is available to be applied to infants, born at GA 24-30 weeks, at birth and also applied during the routine ROP screening process. The tool may allow ophthalmologists to reduce the number of stressful examinations and optimise screening efficiency by potentially and safely releasing many infants from unnecessary eye examinations. DIGIROP-Screen appears to be one of the more robust models predicting severe ROP requiring treatment.

\section{Author affiliations}

'Department of Clinical Neuroscience, Institute of Neuroscience and Physiology, Sahlgrenska Academy, University of Gothenburg, Gothenburg, Sweden

${ }^{2}$ Mary MacKillop Institute for Health Research, Australian Catholic University, Melbourne, Victoria, Australia

${ }^{3}$ Sahlgrenska Osteoporosis Centre, Institute of Medicine, University of Gothenburg, Gothenburg, Sweden

${ }^{4}$ Department of Ophthalmology, Boston Children's Hospital, Harvard Medical School, Boston, Massachusetts, USA

${ }^{5}$ Learning and Leadership for Health Care Professionals, Institute of Health Care Science, Sahlgrenska Academy, University of Gothenburg, Gothenburg, Sweden ${ }^{6}$ Department of Pediatrics, University of Utah School of Medicine, Salt Lake City, Utah, USA

${ }^{7}$ Department of Ophthalmology, John A Moran Eye Center, University of Utah, Salt Lake City, Utah, USA

${ }^{8}$ Department of Ophthalmology, University Medicine Greifswald, Greifswald, Germany

${ }^{9}$ Department of Ophthalmology, Eye Center, Medical Center, Faculty of Medicine, University of Freiburg, Freiburg, Germany

${ }^{10}$ Department of Clinical and Experimental Medicine, Linköping University, Linköping, Sweden

${ }^{11}$ Department of Neuroscience/Ophthalmology, Uppsala University, Uppsala, Sweden ${ }^{12}$ Department of Ophthalmology, Faculty of Medicine and Health, Örebro University, Örebro, Sweden

${ }^{13}$ Department of Clinical Sciences, Ophthalmology, Skåne University Hospital, Lund University, Lund, Sweden

${ }^{14}$ Länssjukhuset Ryhov, Jönköping, Sweden

${ }^{15}$ St. Erik Eye Hospital, Stockholm, Sweden

${ }^{16}$ Department of Physiology/Endocrinology, Institute of Neuroscience and Physiology, Sahlgrenska Academy, University of Gothenburg, Gothenburg, Sweden

${ }^{17}$ Mathematical Sciences, Chalmers University of Technology, Gothenburg, Sweden

${ }^{18}$ Institute of Biomedicine, Sahlgrenska Academy, University of Gothenburg,

Gothenburg, Sweden

Acknowledgements We would like to acknowledge and thank the following persons: Associate Professor Aimon Niklasson at Queen Silvia's Children Hospital for very valuable discussions regarding infants' growth patterns; Lena Kjellberg, Carola Pfeiffer Mosesson, Ulrika Sjöbom and Margareta Höök Wikstrand at Queen Silvia's Children Hospital for performing the WINROP calculations and the validation of SWEDROP data. Marie Saric at Department of Ophthalmology, Umeå University, for data collection in SWEDROP, Gerd Holmström, register holder for SWEDROP, at Department of Neuroscience/Ophthalmology, Uppsala University, all ROP screening ophthalmologists in Sweden working daily with the infants included in our study.

Contributors AP and AH had full access to all of the data in the study and took responsibility for the integrity of the data and the data analysis accuracy. AP, HJ, LEHS, A-LH, CL, KA-W, SN and AH were involved in concept and design. Acquisition of data was done by BAY, MEH, CW, M-CB, WL, AS, AA-H, EL, PL, LG, BS, KT, AW, $\mathrm{GH}$ and $\mathrm{AH}$. Analysis or interpretation of data was done by $\mathrm{AP}, \mathrm{HJ}, \mathrm{LEHS}, \mathrm{A}-\mathrm{LH}, \mathrm{CL}$, KA-W, SN and AH. Drafting of the manuscript was done by AP. All authors made critical revision of the manuscript for important intellectual content. All authors gave approval of the final manuscript. AP, HJ, SN and AH were involved in statistical analyses. AH obtained funding. Administrative, technical or material support was provided by BAY, MEH, CW, M-CB, WL, AS, AA-H, EL, PL, LG, BS, KT, AW, GH and AH.

Funding This study was supported by the Swedish Medical Research Council (\#2016-01131), The Gothenburg Medical Society and Government grants under the ALF agreement (ALFGBG-717971), De Blindas Vänner (no grant number), Knut and Alice Wallenberg Clinical Scholars (no grant number) and Örebro County Council Research Committee (no grant number). LEHS was supported by National Eye Institute (EY017017 and EY030904) and National Institute of Health (1U54HD090255)

Disclaimer The funders had no role in the study design, data collection, statistical analyses or interpretation of the results.

Competing interests None declared.

Patient consent for publication Not required.

Ethics approval The ethics committee of the Faculty of Medicine, Uppsala University, Dnr 2010-117/2, approved this study. The institutional review boards at respective centres approved the use of US data.

Provenance and peer review Not commissioned; externally peer reviewed.

Data availability statement Data may be obtained from a third party and are not publicly available. All data relevant to the study are included in the article or uploaded as supplementary information.

Supplemental material This content has been supplied by the author(s). It has not been vetted by BMJ Publishing Group Limited (BMJ) and may not have 
been peer-reviewed. Any opinions or recommendations discussed are solely those of the author(s) and are not endorsed by BMJ. BMJ disclaims all liability and responsibility arising from any reliance placed on the content. Where the content includes any translated material, BMJ does not warrant the accuracy and reliability of the translations (including but not limited to local regulations, clinical guidelines, terminology, drug names and drug dosages), and is not responsible for any error and/or omissions arising from translation and adaptation or otherwise.

Open access This is an open access article distributed in accordance with the Creative Commons Attribution Non Commercial (CC BY-NC 4.0) license, which permits others to distribute, remix, adapt, build upon this work non-commercially, and license their derivative works on different terms, provided the original work is properly cited, appropriate credit is given, any changes made indicated, and the use is non-commercial. See: http://creativecommons.org/licenses/by-nc/4.0/.

\section{ORCID iDs}

Aldina Pivodic http://orcid.org/0000-0002-2224-3236

Andreas Stahl http://orcid.org/0000-0002-8013-7597

Eva Larsson http://orcid.org/0000-0001-9674-0094

Pia Lundgren http://orcid.org/0000-0002-7731-1988

Gerd Holmström http://orcid.org/0000-0002-5600-7186

Ann Hellström http://orcid.org/0000-0002-9259-1244

\section{REFERENCES}

1 Lee J, Dammann 0. Perinatal infection, inflammation, and retinopathy of prematurity. Semin Fetal Neonatal Med 2012;17:26-9.

2 Mora JS, Waite C, Gilbert CE, et al. A worldwide survey of retinopathy of prematurity screening. Br J Ophthalmol 2018;102:9-13.

3 Mitchell AJ, Green A, Jeffs DA, et al. Physiologic effects of retinopathy of prematurity screening examinations. Adv Neonatal Care 2011;11:291-7.

4 Szigiato A-A, Speckert M, Zielonka J, et al. Effect of eye masks on neonatal stress following dilated retinal examination: the MASK-ROP randomized clinical trial. JAMA Ophthalmol 2019. doi:10.1001/jamaophthalmol.2019.3379. [Epub ahead of print: 05 Sep 2019].

5 Moral-Pumarega MT, Caserío-Carbonero S, De-La-Cruz-Bértolo J, et al. Pain and stress assessment after retinopathy of prematurity screening examination: indirect ophthalmoscopy versus digital retinal imaging. BMC Pediatr 2012;12:132.

6 Zupancic JAF, Ying G-S, de Alba Campomanes A, et al. Evaluation of the economic impact of modified screening criteria for retinopathy of prematurity from the postnatal growth and ROP (G-ROP) study. J Perinatol 2020;40:1100-8.

7 Holmström G, Hellström A, Gränse L, et al. New modifications of Swedish ROP guidelines based on 10-year data from the SWEDROP register. Br I Ophthalmol 2020;104:943-9.

8 Quinn GE, Ying G-S, Bell EF, et al. Incidence and early course of retinopathy of prematurity: secondary analysis of the postnatal growth and retinopathy of prematurity (G-ROP) study. JAMA Ophthalmol 2018;136:1383-9.

9 Blencowe H, Lawn JE, Vazquez T, et al. Preterm-associated visual impairment and estimates of retinopathy of prematurity at regional and global levels for 2010. Pediatr Res 2013;74 Suppl 1:35-49.

10 Kim SJ, Port AD, Swan R, et al. Retinopathy of prematurity: a review of risk factors and their clinical significance. Surv Ophthalmol 2018;63:618-37.

11 Löfavist C, Andersson E, Sigurdsson J, et al. Longitudinal postnatal weight and insulinlike growth factor I measurements in the prediction of retinopathy of prematurity. Arch Ophthalmol 2006;124:1711-8.

12 Hellström A, Hård A-L, Engström E, et al. Early weight gain predicts retinopathy in preterm infants: new, simple, efficient approach to screening. Pediatrics 2009:123:e638-45.

13 Slidsborg C, Forman JL, Rasmussen S, et al. A new risk-based screening criterion for treatment-demanding retinopathy of prematurity in Denmark. Pediatrics 2011;127:e598-606.

14 Eckert GU, Fortes Filho JB, Maia M, et al. A predictive score for retinopathy of prematurity in very low birth weight preterm infants. Eye 2012;26:400-6.

15 Binenbaum G, Ying G-S, Quinn GE, et al. The CHOP postnatal weight gain, birth weight, and gestational age retinopathy of prematurity risk model. Arch Ophthalmol 2012;130:1560-5.
$16 \mathrm{Cao} \mathrm{JH}$, Wagner BD, Cerda A, et al. Colorado retinopathy of prematurity model: a multi-institutional validation study. J Aapos 2016;20:220-5.

17 Binenbaum G, Ying G-S, Tomlinson LA, et al. Validation of the children's Hospital of Philadelphia retinopathy of prematurity (CHOP ROP) model. JAMA Ophthalmol 2017; 135:871-7.

18 McCauley K, Chundu A, Song H, et al. Implementation of a clinical prediction model using daily postnatal weight gain, birth weight, and gestational age to risk stratify ROP. J Pediatr Ophthalmol Strabismus 2018:55:326-34.

19 Binenbaum G, Bell EF, Donohue P, et al. Development of modified screening criteria for retinopathy of prematurity: primary results from the postnatal growth and retinopathy of prematurity study. JAMA Ophthalmol 2018;136:1034-40.

20 Ahmed IS, Badeeb AA. The Alexandria retinopathy of prematurity model (Alex-ROP): postnatal weight gain screening algorithm application in a developing country. Int $J$ Ophthalmol 2019:12:296-301.

21 Hutchinson AK, Melia M, Yang MB, et al. Clinical models and algorithms for the prediction of retinopathy of prematurity: a report by the American Academy of ophthalmology. Ophthalmology 2016;123:804-16.

22 Wu C, Löfquist C, Smith LEH, et al. Importance of early postnatal weight gain for normal retinal angiogenesis in very preterm infants: a multicenter study analyzing weight velocity deviations for the prediction of retinopathy of prematurity. Arch Ophthalmol 2012;130:992-9.

23 Löfquist C, Hansen-Pupp I, Andersson E, et al. Validation of a new retinopathy of prematurity screening method monitoring longitudinal postnatal weight and insulinlike growth factor I. Arch Ophthalmol 2009;127:622-7.

24 Pivodic A, Hård A-L, Löfquist C, et al. Individual risk prediction for sightthreatening retinopathy of prematurity using birth characteristics. JAMA Ophthalmol 2019:1-9.

25 Equator. Tripod guidelines. Available: https://www.equator-network.org/reporting guidelines/tripod-statement/ [Accessed 22 Dec 2020]

26 Medscinet. SNQ register. Available: https://www.medscinet.com/pnq/default.aspx [Accessed 22 Dec 2020].

27 Larsen PP, Bründer M-C, Petrak M, et al. [Screening for retinopathy of prematurity: Trends over the past 5 years in two German university hospitals]. Ophthalmologe 2018;115:469-75.

28 Engle WA. American Academy of pediatrics Committee on F, newborn. age terminology during the perinatal period. Pediatrics 2004;114:1362-4.

29 Niklasson A, Albertsson-Wikland K. Continuous growth reference from 24th week of gestation to 24 months by gender. BMC Pediatr 2008;8:8.

30 Early Treatment For Retinopathy Of Prematurity Cooperative Group. Revised indications for the treatment of retinopathy of prematurity: results of the early treatment for retinopathy of prematurity randomized trial. Arch Ophthalmol 2003:121:1684-94.

31 International Committee for the Classification of Retinopathy of Prematurity. The International classification of retinopathy of prematurity revisited. Arch Ophthalmol 2005; 123:991-9

32 DIGIROP. Welcome to DIGIROP. Available: https://www.digirop.com/ [Accessed 22 Dec 2020].

33 Binenbaum G. Algorithms for the prediction of retinopathy of prematurity based on postnatal weight gain. Clin Perinatol 2013;40:261-70.

34 Binenbaum G, Tomlinson LA, de Alba Campomanes AG. Validation of the postnatal growth and retinopathy of prematurity screening criteria. JAMA Ophthalmo/2019.

35 Valikodath N, Cole E, Chiang MF. Imaging in retinopathy of prematurity. Asia Pac J Ophthalmol 2019;8:178-86

36 Wilkinson AR, Haines L, Head K, et al. Uk retinopathy of prematurity guideline. Early Hum Dev 2008:84:71-4.

37 American Academy of Pediatrics Section on Ophthalmology, American Academy of Ophthalmology, The American Association for Pediatric Ophthalmology and Strabismus. Screening examination of premature infants for retinopathy of prematurity. Pediatrics 2018;142.

38 Augenärztliche Screening-Untersuchung bei Frühgeborenen. German ROP screening guideline (Augenärztliche Screening-Untersuchung bei Frühgeborenen). Available: https://www.awmf.org/uploads/tx_szleitlinien/024-010l_S2k_Augenaerztliche_ Screening-Untersuchung_Fr\%CC3\%BChgeborene_2020-07.pdf [Accessed 22 Dec 2020]. 